\title{
SISTEM SIARAN DIGITAL VIDEO BROADCASTING TERESTRIAL 2 (DVB-T2) DI SCTV BATAM
}

\author{
Toni Kusuma Wijaya \\ Dosen Tetap Prodi Teknik Elektro UNRIKA Batam
}

\begin{abstract}
Populernya teknologi Broadcast dengan transmisi Digital menggeser teknologi transmisi analog. Teknologi broadcast digital membutuhkan bandwidth yang lebih lebar, memiliki fleksibilitas yang tinggi. Siaran televisi digital menyajikan gambar dan suara yang jauh lebih stabil dan resolusi lebih tajam, ini dimungkinkan oleh penggunaan sistem Orthogonal Frequency Division Multiplexing (OFDM) yang mampu mengatasi efek lintas jamak (multipath), sehingga televisi digital menawarkan kualitas gambar yang sama dengan kualitas DVD (Digital Versatile/Video Disc), dan kualitas suara pun mampu mencapai kualitas CD (Compact Disk). Bagaimana penggunaan frekuensi pada sistem penyiaran digital dapat diefisienkan ? Jawabannya terletak pada penggunaan teknologi OFDM sebagai teknik modulasi. Dengan OFDM, frekuensi dengan lebar bandwidth tertentu dibagi-bagi menjadi sejumlah subcarrier sehingga memungkinkan sejumlah program dapat dikirimkan melalui sebuah frekuensi carrier. Proses siaran televisi digital yang menggunakan standar Digital Video Broadcasting Terestrial 2 (DVBT2) di Stasiun Transmisi SCTV Batam dimulai dari penerimaan dengan parabola yang diteruskan ke Integrated Receiver Decoder (IRD) yang mana ini adalah dalam satu blok diagram yaitu Television Receiver Only (TVRO). Output dari IRD masuk ke input Multiplexer ( MUX ) dan output Mux menuju sistem DVB T2 itu sendiri dan outputnya langsung diinputkan ke transmitter untuk dipancarkan. Dengan TV digital, satu frekuensi dapat digunakan untuk 6-8 siaran yang berbeda. Dengan keunggulan ini, keterbatasan jumlah kanal dalam spektrum frekuensi siaran dapat diatasi dan memungkinkan munculnya stasiun-stasiun televisi baru yang lebih banyak .
\end{abstract}

Di Indonesia terdapat 11 Stasiun TV berizin siaran nasional serta sekitar 300 izin baru yang tidak terlayani karena keterbatasan kanal TV UHF. Saluran TV analog yang menggunakan gelombang Ultra High Frequency (UHF), hanya mampu digunakan 14 kanal frekuensi UHF stasiun pemancar TV. Jika dipaksakan akan terjadi interferensi satu sama lain yang membuat suara dan gambar yang ditampilkan akan menjadi rusak.

Saat ini berbagai negara telah memutuskan untuk migrasi dari teknologi penyiaran TV analog ke digital. Hal tersebut dilakukan karena penyiaran TV dengan teknologi digital mempunyai banyak keunggulan dibandingkan dengan penyiaran TV dengan teknologi analog.

Peraturan Menteri Komunikasi dan Imformatika Nomor 22/PER/M. KOMINFO/11/2011 tentang Penyelenggara Penyiaran Televisi Digital Terestrial Penerimaan Tetap Tidak berbayar, bahwa perkembangan teknologi penyiaran televisi terestrial di dunia saat ini beralih dari sistem penyiaran analog ke sistem penyiaran digital maka di Indonesia ditetapkan sebagai standar penyiaran televisi digital terestrial tetap tidak berbayar adalah DVB -T2 ( Digital Video Broadcasting - Terestrial ). 
Sistem Penyiaran Televisi Analog

Televisi analog adalah televisi yang umum kita jumpai saat ini. Disebut analog karena data (isi siarannya) berbentuk analog. Siaran analog dilakukan dengan cara merekam gambar dan suara, lalu mengubahnya menjadi gelombang, kemudian gelombang ini dipancarkan oleh stasiun televisi. Jenis gelombang yang dipancarkan stasiun televisi adalah VHF/UHF. Gelombang ini dipancarkan terus-menerus setiap detik, Jika dalam satu detik dipancarkan gelombang sebanyak sepuluh kali, maka kecepatan gelombangnya 10 Hertz.

\subsection{Sistem Penyiaran Televisi Digital}

Televisi digital atau DTV adalah jenis televisi yang menggunakan modulasi digital dan sistem kompresi untuk menyiarkan sinyal gambar, suara, dan data ke pesawat televisi. TV digital memiliki peralatan suara dan gambar berformat digital.TV digital ditunjang oleh teknologi penerima yang mampu beradaptasi sesuai dengan lingkungannya.

Perbandingan lebar pita frekuensi yang digunakan teknologi analog dengan teknologi digital adalah 1: 6. Jadi, bila teknologi analog memerlukan lebar pita $8 \mathrm{MHz}$ untuk satu kanal transmisi, teknologi digital dengan lebar pita yang sama (menggunakan teknik multipleks) dapat memancarkan sebanyak 6 hingga 12 kanal transmisi sekaligus untuk program yang berbeda. Semua standar sistem pemancar TV digital berbasiskan OFDM dengan teknik pengkodean MPEG2/MPEG4.

TV digital memiliki beberapa kelebihan jika dibandingkan dengan televisi analog, yaitu :

1. Kualitas gambar dan suara

Siaran televisi digital menyajikan gambar dan suara yang jauh lebih stabil dan resolusi lebih tajam dibandingkan dengan siaran analog. Hal ini dimungkinkan oleh penggunaan sistem Orthogonal Frequency Division Multiplexing (OFDM) yang mampu mengatasi efek lintas jamak (multipath). Pada sistem analog, efek lintasan jamak menimbulkan echo atau gaung yang berakibat munculnya gambar ganda (seakan ada bayangan).

2. Tahan perubahan lingkungan

Siaran televisi digital memiliki ketahanan terhadap perubahan lingkungan yang terjadi karena pergerakan pesawat penerima ( mobile TV), sehingga tidak terjadi gambar bergoyang atau berubah -ubah kualitasnya seperti pada TV analog saat ini.

3. Tahan terhadap efek interferensi

Siaran televisi digital memiliki ketahanan terhadap efek interferensi, derau dan fading, serta mudah proses perbaikan (recovery) sinyal yang rusak akibat proses pengiriman atau transmisi sinyal. Perbaikan akan dilakukan di bagian penerima dengan kode koreksi error (error correction code) tertentu.

4. Efisien dalam penggunaan spektrum/kanal

Dengan TV digital, satu frekuensi dapat digunakan untuk 6-12 siaran yang berbeda. Ini jauh lebih efisien dibanding dengan siaran analog dimana satu frekuensi hanya untuk satu siaran saja.

\subsection{Video Digital}

Video digital pada dasarnya merupakan serangkaian gambar digital yang di tampilkan dengan cepat pada kecepatan konstan. Dalam konteks video, gambar ini disebut frame. Satuan ukuran untuk menghitung frame rata-rata yang ditampilkan disebut frame per 
second (fps). Setiap frame merupakan gambar digital yang terdiri dari raster piksel. Gambar digital ini mempunyai lebar $\mathrm{W}$ piksel dan tinggi $\mathrm{H}$ piksel, sehingga dikatakan bahwa frame size adalah $\mathrm{WxH}$.

Beberapa properti dari sebuah video adalah sebagai berikut :

1. Pixel per frame $=$ lebar $(\mathrm{W}) \mathrm{x}$ tinggi $(\mathrm{H})$

2. Bit per frame $=$ pixel per frame $\mathrm{x}$ color depth

3. Bit rate $(\mathrm{BR})=$ bit per frame $x$ frame rate

4. Video size $(\mathrm{VS})=$ bit rate $\mathrm{x}$ durasi video

Contoh :

Sebuah video mempunyai durasi 1 jam $(3.600 \mathrm{sec})$, frame size 640x480 pixel dengan color depth 24 bit, dan frame rate 25 fps akan mempunyai properti sebagai berikut :

1. Pixel per frame $=640 \times 480=307.200$

2. Bit per frame $=307.200 \times 24=7.372 .800=7,37 \mathrm{Mbit}$

3. Bit rate $(\mathrm{BR})=7,37 \times 25=184,25 \mathrm{Mbit} / \mathrm{sec}$

4. Video size $(\mathrm{VS})=184 \mathrm{Mbit} / \mathrm{sec} \times 3.600 \mathrm{sec}=662.400 \mathrm{Mbit}$

\subsection{Teknik Kompresi Video Digital}

Kompresi adalah sebuah konversi data ke sebuah format yang lebih kecil, biasanya dilakukan sehingga data dapat disimpan atau disalurkan lebih efisien. Teknik kompresi erat hubungannya dengan encoding (pengkodean), sedangkan proses pengembalian data yang sudah dikecilkan tersebut disebut dekompresi.

\subsection{Multiplexing}

Multiplexing adalah teknik menggabungkan beberapa sinyal untuk dikirimkan

secara bersamaan pada suatu kanal transmisi. Perangkat yang digunakan untuk melakukan multiplexing dinamakan sebagai multiplexer (Mux). Di sisi penerima, sinyal yang telah digabungkan dipisahkan kembali (di-demultiplexing) sesuai dengan tujuan masing-masing dengan menggunakan perangkat yang disebut demultiplexer (Demux).

\subsection{Modulasi}

Modulasi adalah proses penumpangan informasi yang terkandung dalam sebuah rentang frekuensi pada sebuah frekuensi pembawa. Proses kebalikan dari modulasi disebut demodulasi. Contoh modulasi adalah proses penyiaran suara atau musik yang dipancarkan melalui sebuah pemancar radio. Sedangkan contoh demodulasi adalah proses penerimaan suara atau musik oleh sebuah pesawat penerima radio. Modulasi digunakan untuk mengatasi ketidaksesuaian karakter sinyal dengan media (kanal) yang digunakan. Dalam modulasi digital, suatu sinyal analog dimodulasi berdasarkan aliran data digital.

Teknik yang umum dipakai adalah pada modulasi digital adalah :

1. Phase Shift Keying (PSK), digunakan suatu jumlah terbatas berdasarkan fase.

2. Frekeunsi Shift Keying (FSK), digunakan suatu jumlah terbatas berdasarkan frekuensi.

3. Amplitudo Shift Keying (ASK), digunakan suatu jumlah terbatas amplitudo.

4. Quadrature Amplitude Modulation ( QAM ), adalah metode menggabungkan dua amplitudo-modulated (AM) sinyal ke saluran tunggal, adalah jenis modulasi sinyal di mana dua pembawa bergeser dalam fasa 90 derajat. Modulasi QAM kombinasi dari modulasi digital ASK dengan PSK.

5. Orthogonal Frequency Division Multiplexing (OFDM), Orthogonal Frequency Division Multiplexing (OFDM) merupakan kombinasi dari 
teknik modulasi dan multiplexing. Teknik OFDM hampir sama dengan FDM.

SCTV sebagai konsorsium TV digital Indonesia, sedang melakukan migrasi dari analog ke platform siaran sistem digital, yang merupakan bagian dari kebijakan pemerintah yang mana saat ini sedang uji coba.
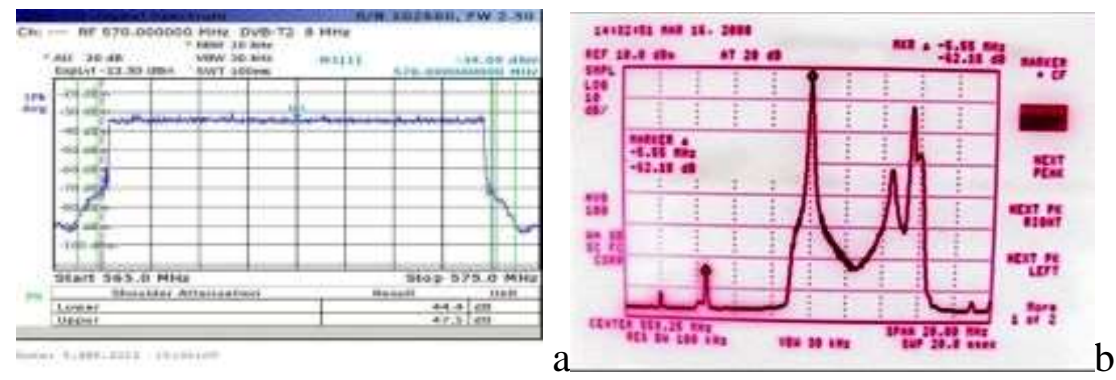

Gambar 5.4 a. Bandwith Sinyal digital dan b. Bandwith Sinyal analog

Sumber : File Data pengukuran Enginering dept. SCTV, Sept, 2012.

Pada layar spectrum gambar 5.4 (a) sinyal digital menjadi titik referensi carrier adalah center carrier ( tulisan M1). Sedangkan pada analog (b) yang menjadi titik referensi adalah sinyal video ( pucuk sinyal yang paling tinggi).

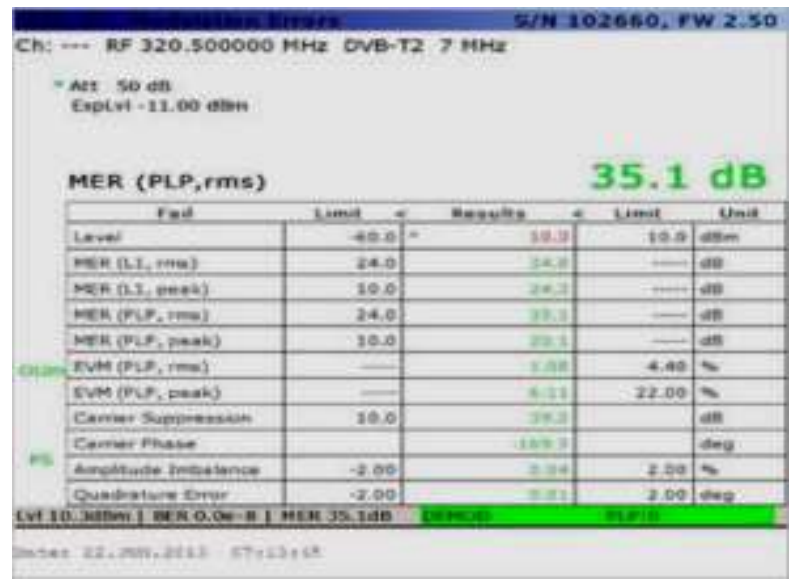

\section{Gambar 5.6 MER}

MER (Modulation Error Ratio) dalam dB untuk memberitahukan seberapa baik pemancar mampu mereproduksi sinyal DVB dan biasanya di urutan 35dB atau lebih. MER adalah salah satu indikator kesehatan pemancar. MER adalah ukuran rasio signal-to-noise (SNR) dalam sinyal termodulasi digital untuk menentukan kinerja sistem dalam aplikasi komunikasi digital. MER pada dasarnya, ukuran dari "ketidak jelasan" pendaratan simbol konstelasi data, dihitung sebagai rasio dalam $\mathrm{dB}:$ MER $(\mathrm{DB})=10 \mathrm{x} \log$ (rata rata symbol power/rata rata error power). MER diukur dengan menggunakan digital spectrum analyzer. MER : Semakin tinggi lebih baik.

Implementasi Sistem DVB-T2 di Stasiun Transmisi SCTV Batam 
Pada gambar 6.1, dapat dilihat bahwa implementasi sistem DVB-T2 di stasiun transmisi Batam secara umum dibagi menjadi 4 bagian utama yaitu headend, Multiplexer (Mux), sistem DVB-T2 dan bagian pemancar (TX).

a. Headend terdiri atas perangkat antena parabola penerima, sejumlah perangkat IRD (Integrated Receiver Decoder) dan sejumlah multiplexer. IRD merupakan interface antara parabola dengan fasilitas broadcast video/audio. IRD yang dipakai SCTV merk Harmonic Proview 7100.

b. Multiplexer digunakan untuk menggabungkan beberapa program menjadi sebuah stream. Stasiun relay dalam sistem penyiaran TV digital bertugas menggabungkan (memultiplex) sejumlah program kemudian ditransmisikan kembali ke penerima akhir. Mux3 digunakan untuk menggabungkan program-program yang diterima dari pemancar pusat dengan konten lokal.

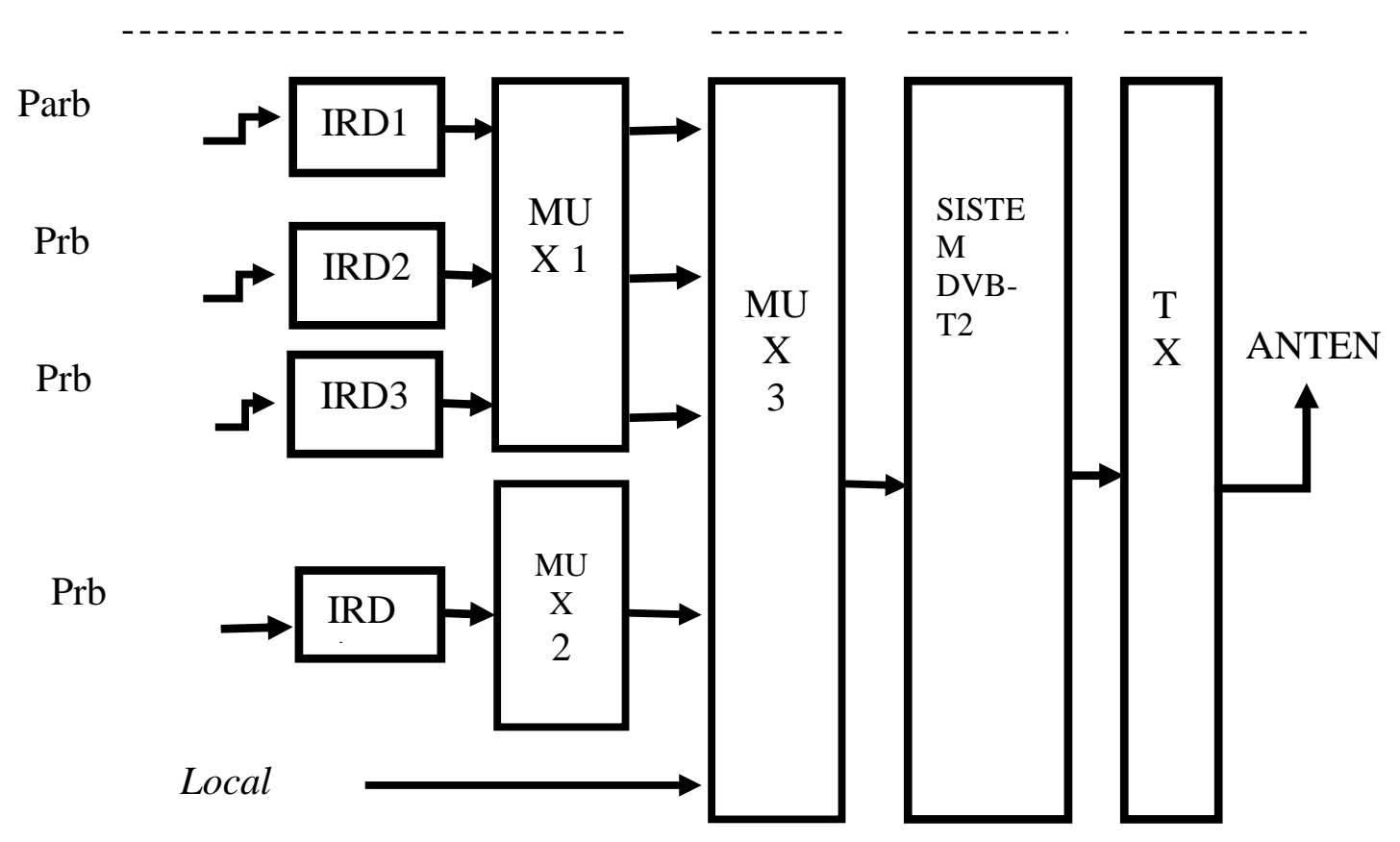

Gambar 6.1 Blok diagram sistem DVB-T2 SCTV Batam

c. Sistem DVB-T2 pada gambar 6.1 berfungsi untuk memodulasi sejumlah program yang telah dimultiplex untuk selanjutnya ditransmisikan pada sebuah frekuensi carrier dengan lebar bandwidth sebesar $8 \mathrm{MHz}$.

d. TX ( transmitter), Transmitter berfungsi untuk memancarkan semua imformasi supaya bisa ditangkap oleh televisi pemirsa.

Perbedaan pokok teknologi penyiaran digital dan penyiaran analog adalah adanya peralatan multiplexer (mux). Multiplexer merupakan suatu sistem perangkat untuk menyalurkan beberapa program siaran dari para Penyelenggara Program Siaran yang kemudian dipancarkan kepada 
masyarakat/pemirsa melalui suatu perangkat transmisi. Teknologi multiplexing ini sendiri memungkinkan dilakukannya pelebaran kanal frekuensi. Dalam sistem analog, satu kanal (frekuensi) hanya bisa diisi satu saluran program, sedangkan dalam sistem digital satu kanal (frekuensi) bisa diisi dengan lebih dari enam saluran program sekaligus.

Bagaimana penggunaan frekuensi pada sistem penyiaran digital dapat diefisienkan ? Jawabannya terletak pada penggunaan teknologi OFDM sebagai teknik modulasi. Dengan OFDM, frekuensi dengan lebar bandwidth tertentu dibagi-bagi menjadi sejumlah subcarrier sehingga memungkinkan sejumlah program dapat dikirimkan melalui sebuah frekuensi carrier. Penjelasan lebih detail tentang OFDM dapat dilihat di Bab 2.

Dari pembahasan tersebut diatas dapat disimpulkan bahwa : Dengan teknologi Digital Vidio Broadcasting Terestrial 2 dapat membawa dan memodulasi berbagai tipe program didalam satu bandwith frekuensi, jika dibanding dengan analog hanya membawa satu program dalam satu bandwith.

Saran

Teknologi DVB-T2 adalah teknologi terbaru dalam dunia pertelevisian digital di Indonesia masih bisa dan sangat menarik untuk dipelajari dan dikaji lebih mendalam lagi.

\section{DAFTAR KEPUSTAKAAN}

- $\quad$ Deniau Eric, DVB-T2 DEPLOYMENT,April $20^{\text {th }}$ 2012, TRIESTE

- Floyd. J Thomas, Digital Fundamentals $8^{\text {th }}$ edition, 2003, England UK

- Ibrahim K.F, Teknik Digital, 1996, CV.Andi Offset, Yokyakarta

- Leong Tan Hock, Digital TV Implementation, March 2013, Rohde \& Schwarz Certified trainer, Kuala Lumpur

- Muhsin Muhammad, Elektronika digital, 2004, CV.Andi Offset, Yokyakarta

- Manual books EBU TECH 3348, Frequency and Network Planning Aspects of DVB-T2, Mei 2012, Geneva

- Nils Ahren, Managing DVB-T2 Broadcast Transmission Networks, 2011, Rohde \& Schwarz

- Widjanarka N Wijaya. Ir , Teknik Digital, 2006, Erlangga ,Jakarta

- Zuhal.Prof.Dr. M.Sc.EE, Prinsip Dasar Elektroteknik, 2004, Pt Gramedia Pustaka Utama, Jakarta. 